\title{
sciendo
}

\section{Actual Playing Time of Water Polo Players in Relation to the Field Position}

\author{
by \\ Giovanni Melchiorri, ${ }^{1,2}$,Valerio Viero ${ }^{3,4}$, Virginia Tancredi5, Roberto Del Bianco ${ }^{3}$, \\ Marco Bonifazi $i^{3,6}$
}

\begin{abstract}
In water polo competitions, teams play four periods, each period consisting of eight minutes of actual playing time: a total of 32 minutes (Standard Actual Play Time, SAPT). Substitutions are permitted and a player may be substituted several times. The aim of this article was to provide reference data on played time, taking into consideration the field play position of the players. 352 male water polo players of 18 different nationalities were studied during two consecutive FINA World Championships. 180 games were analyzed and 1980 measurements of the game Measured Actual Play Time (MAPT) were taken. A time density index (DI) was calculated for each athlete using SAPT and MAPT. No statistically significant differences between the field positions were found with regard to age, as was the case in relation to teams between Game MAPT, Tournament MAPT and DI. However, when looking at the diverse field positions (field players, FP; center forward, $C F$; center back, $C B$ ), there were statistically significant differences: Game $M A P T$ FPvsCB $p=0.03$ and FPvsCF $p=0.03$; Tournament MAPT FPvsCB $p=0.03 ;$ DI FPvsCB $p=0.03$ and FPvsCF $p=0.04$. In these competitions the water polo player had on average a MAPT value of $17.4 \pm 6.1 \mathrm{~min}$ (54.6 \pm 9.5\% DI); there were athletes who played $2.3 \mathrm{~min}(7.1 \% \mathrm{DI})$ and others who played up to $31.6 \mathrm{~min}(95.3 \% \mathrm{DI})$. The MAPT in water polo is extremely variable among athletes and must be considered for a correct performance analysis. High-level water polo players require different training strategies depending on their MAPT.
\end{abstract}

Key words: match analysis, field position, age, periodization, training strategies.

\section{Introduction}

Water polo is a highly demanding and complex team sport, requiring repeated sprints at maximum speed interspersed with swimming at lower speeds during the game, often with changes of direction. Furthermore, it requires technically skilled movements and contact with the opponent involving changing from a vertical to a horizontal position while playing (Galy et al., 2014; Melchiorri et al., 2010; Smith, 1998). Change of game rules by Federation Internationale de
Natation (FINA) in 2005 made playing even more demanding (Melchiorri et al., 2010), increasing the overall game duration and reducing the time of ball possession per team (Platanou et al., 2007). For these reasons, water polo players have to train hard to ensure good performance during the game.

In a water polo game each team consists of thirteen players: eleven field players and two goalkeepers. A team starts the game with no more than seven players, one of whom is the

\footnotetext{
1 - School of Sport and Exercise Sciences, Department of Systems Medicine, Faculty of Medicine and Surgery, University of Roma Tor Vergata, Via Montpellier, 100133 Rome, Italy.

2 - Don Gnocchi Foundation IRCS, Milano, Italy.

3 - Italian Swimming Federation, Rome, Italy.

4 - School of Sport and Exercise Sciences, Faculty of Medicine and Surgery, University of Roma Tor Vergata, Via Montpellier, 1 00133 Rome, Italy.

5 - Department of Systems Medicine and Centre of Space BioMedicine, University of Rome Tor Vergata, Rome, Italy.

6 - Department of Medicine, Surgery and Neuroscience, University of Siena, Siena, Italy.
} 
goalkeeper. Five reserves may be used as substitutes for the field players, but only one for the goalkeeper. Substitutions are possible at any time during the game, and a player may be substituted several times (FINA, 2018). In other team sports, especially indoor or small field sports, players may likewise be substituted several times, and unlimited substitution is often permitted (basketball, futsal, handball, etc). Consequently, the time played by the individual athlete in a game can vary greatly. This affects performance variables in such a way that performance of one player is potentially completely different from another's, even during the same match.

To be effective the training process requires an observation phase, an analysis phase and a planning phase (Franks and Goodman, 1986). In this process, performance analysis data are essential to design and implement successful short-term and long-term training programs.

Therefore, performance variables (physiological, game activity and technical ones) observed during the games are fundamental for the creation of a performance and training model specific to a given sport and are decisive for coaching intervention (Franks and Miller, 1991). Observing competition is also essential to evaluate performance of players during the game and to plan and prepare for future competitions (Huges, 2015).

There is a lot of research on types, duration and incidence, as well as effects of players' different activities during the game (Melchiorri et al., 2010; Platanou, 2004; Platanou and Geladas, 2006; Smith, 1991). One study also reported data on female players' periods of inactivity in a game (Tan et al., 2009), whereas comparable data in male players are not available and no research seems to be available on actual played time. Our analysis of the international literature (up to February 2018, key words: waterpolo or water polo and time motion analysis, played time, play time, game activity, performance analysis, notational analysis), has not revealed any information about the actual playing time of the athletes. Studies reporting on actual play time in other team sports (basketball and handball) do not seem to have been conducted yet either.

Based on all these reasons, the aim of this article was to provide reference data on played time in relation to the players' field positions in water polo.

\section{Methods}

\section{Participants}

The study involved 352 male water polo players of 18 different national teams. The average age of the sample was $26.3 \pm 4.1$ years. The time played by the athletes (Measured Actual Play Time, MAPT) was measured in 180 games for a total of 1980 measurements. Athletes studied were divided according to their positions, on the basis of what is known from the literature (Melchiorri et al., 2010). Goalkeepers were not considered in the study.

The study was approved by the ethics committee of the Swimming National Federation. As the study is a notational analysis on public access data, no informed consent was needed.

\section{Measures}

An analysis was conducted on all of the games played during two consecutive FINA Men's World Championships (Kazan 2015 and Budapest 2017). The national teams studied in both competitions were: Australia, Brazil, Canada, Croatia, Greece, Italy, Japan, Kazakhstan, Montenegro, South Africa, Hungary, Russia, Serbia, and the USA, whereas those analyzed in one of the two competitions were: Argentina, China, France, and Spain. The games analyzed were in total 180: 90 in Kazan and 90 in Budapest.

Omega Timing is the official technical support during the FINA World Championship. During the match, a jury of FINA officials (timekeepers, secretaries and referees) cooperate to record team roster, field positions, substitutions, goals, exclusions, game duration, and playing time for each team and player (FINA, 2018). Omega Timing website reports these data. Our data were obtained from the Omega Timing website or calculated using these data (Omega Timing, 2015; Omega Timing, 2017).

\section{Statistical analysis}

Data are presented as mean and standard deviations. When data were expressed in the subgroups as a percentage, considering that the sample exceeded 100 units, they were expressed with a decimal. Data were collected using Excel 2013 software (Microsoft, Redmond, WA) and processed with SPSS 19 software (IBM Inc, 
Armonk, NY). Data sets were checked for normality using normality plots, and Kolmogorov Smirnov and Shapiro-Wilk tests. The homogeneity of variance was studied with the Levene's test. Relationships between variables were assessed using Pearson's product moment correlation. The $p<0.05$ criterion was used for establishing statistical significance. When data were expressed in percentages we used the $\chi^{2}$ test to verify the difference between values. Comparisons between means were performed with analysis of variance with post hoc Bonferroni tests where necessary. Percentiles analysis and Tukey limits $\left(25^{\circ}\right.$ and $75^{\circ}$ percentile) were used for providing the reference data boundary. Four periods, each of 8 minutes (a total of 32 minutes in a game), provided the actual play time as clearly defined by FINA rules (Standard Actual Play Time, SAPT). Using SAPT and MAPT for each athlete, a time density index (DI) was calculated using the formula: (SAPT/MAPT) x 100 (Portney and Watkins, 2009).

\section{Results}

Two consecutive editions of the world championships were evaluated in order to provide more reliable reference data. The athletes considered had different field positions. Of these 191 were field players (FP, mean age: $26.1 \pm 4.2$ years), 77 center forwards (CF, mean age: $26.1 \pm$ 3.9 years) and 84 center backs (CB, mean age: 26.8 \pm 4.3 years). No statistically significant differences were found between the positions with regard to age $\left(\mathrm{CB}_{\mathrm{vs}} \mathrm{CF} p=0.89 ; \mathrm{CB}_{\mathrm{vs}} \mathrm{FP} p=0.57\right.$ and $\mathrm{FP}_{\mathrm{vs}} \mathrm{CF} p$ $=0.91)$. In relation to teams no difference was found between Game MAPT $(p=0.87)$, and Tournament play time MAPT $(p=0.18)$, and DI ( $p$ $=0.90)$.

Table 1 shows the measured data and the mean values in the two editions (2015 and 2017). Athletes tested in the two editions were different in $38.6 \%(p=0.002)$ of the cases. No statistically significant differences were apparent between editions for Game MAPT ( $p=0.86)$, Tournament MAPT $(p=0.88)$, DI $(p=0.8)$.

Table 2 (TOTAL) shows the average data of the values reported in Table 1

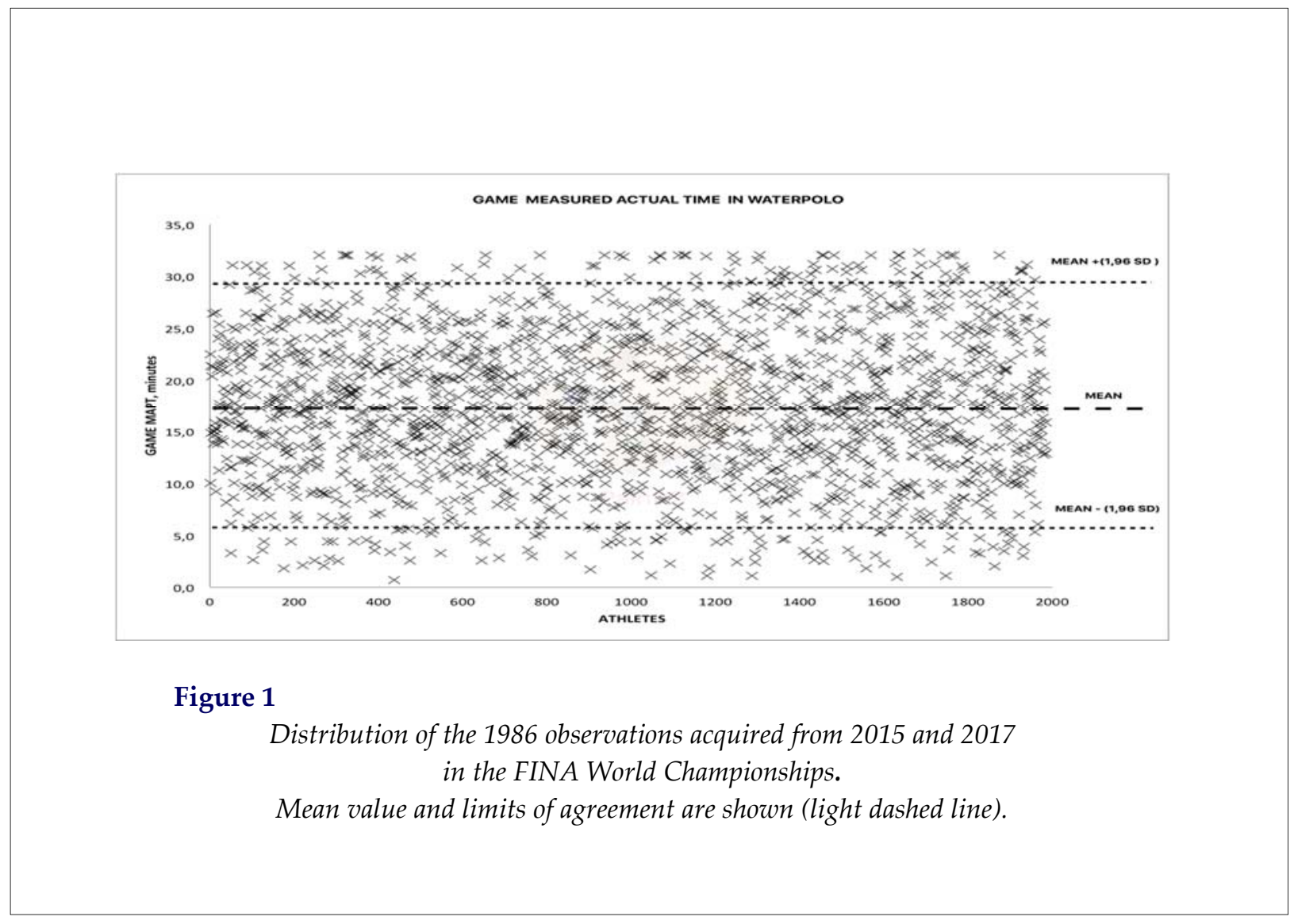

(c) Editorial Committee of Journal of Human Kinetics 
Table 1

Data collected in the two editions of the Water Polo World Championships.

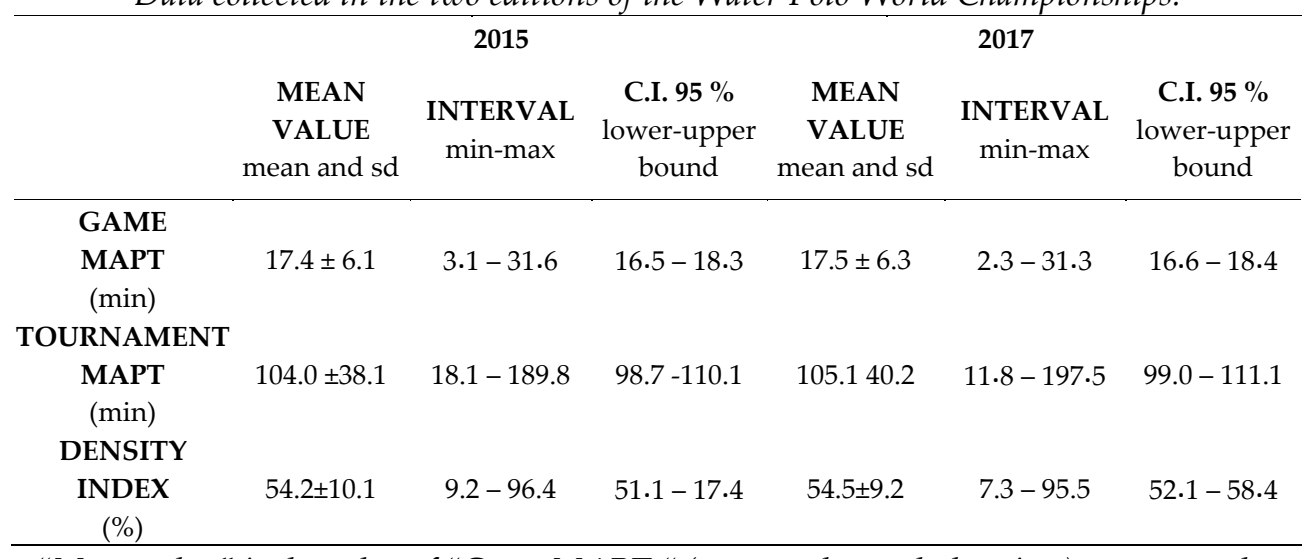

"Mean value" is the value of "Game MAPT" (measured actual play time): average value of actual time measured in a game. "Tournament MAPT" is the total value of minutes played throughout the world championship.

"Density Index" indicates the average percentage of actual time spent playing in a game.

Table 2

Reference values of playing time in water polo (average of the editions 2015 and 2017 of the Water Polo World Championships).

\begin{tabular}{|c|c|c|c|}
\hline & \multicolumn{3}{|c|}{ TOTAL } \\
\hline & $\begin{array}{c}\text { MEAN VALUE } \\
\text { mean and sd }\end{array}$ & $\begin{array}{l}\text { INTERVAL } \\
\text { min-max }\end{array}$ & $\begin{array}{c}\text { C.I. } 95 \% \\
\text { lower-upper } \\
\text { bound }\end{array}$ \\
\hline $\begin{array}{l}\text { GAME MAPT } \\
(\mathrm{min})\end{array}$ & $17.4 \pm 6.1$ & $2.3-31.6$ & $16.8-18.1$ \\
\hline $\begin{array}{l}\text { TOURNAMENT } \\
\text { MAPT } \\
(\min )\end{array}$ & $104.7 \pm 39.1$ & $11.8-197.5$ & $101.6-108.9$ \\
\hline $\begin{array}{l}\text { DENSITY INDEX } \\
(\%)\end{array}$ & $54.6 \pm 9.5$ & $7.1-95.3$ & $52.3-56.7$ \\
\hline
\end{tabular}

"Game MAPT" (average value of actual time measured in a game).

"Tournament MAPT" (total value of minutes played throughout the world championship).

"Density Index" (average percentage of actual time spent playing in a game). 
Table 3

Differences between particular field positions in water polo.

\begin{tabular}{|c|c|c|c|c|}
\hline & & FPs & CBs & CFs \\
\hline $\begin{array}{c}\text { GAME MAPT } \\
(\mathrm{min})\end{array}$ & & $18.3 \pm 6.1$ СF-СВ & $16.3 \pm 5.7$ & $16.3 \pm 6.4$ \\
\hline TOURNAMENT MAPT & $(\mathrm{min})$ & $110.0 \pm 39.3$ Св & $96.1 \pm 36.4$ & $99.9 \pm 39.4$ \\
\hline $\begin{array}{c}\text { DENSITY INDEX } \\
(\%)\end{array}$ & & $59.6 \pm 15.0 \mathrm{CF}-\mathrm{CB}$ & $51.2 \pm 15.0$ & $51.6 \pm 18.0$ \\
\hline
\end{tabular}

Differences are expressed as mean and standard deviation. FPs: field players,

CBs: center backs, CFs: center forwards.

The letters in superscript next to the numbers indicate statistically

significant differences between the groups.

Table 3 shows data related to differences measured in players with particular field positions. Statistically significant differences were apparent regarding the positions of the players: Game MAPT was different and higher in FP than in $\mathrm{CB}(p=0.03)$ and in $\mathrm{CF}(p=0.03)$. Tournament MAPT was different and higher in FP than in CB $(p=0.03)$. The Density Index changed in field positions, just as the Game MAPT, and was higher in FP than in $\mathrm{CB}(p=0.03)$ and in $\mathrm{CF}(p=$ $0.04)$.

The relationship between the age of the athletes and the played time was also studied. In our sample there was a slight correlation between age and the Game MAPT $(r=0.22$ and $p=0.001)$ and between age and the MAPT Tournament $(\mathrm{r}=$ 0.26 and $p=0.002$ ).

Figure 1 shows the distribution of the observations around the mean value. The limits of agreement indicated the interval in which $95 \%$ of differences lay. The upper limit of agreement was $29.4 \mathrm{~min}$ and the lower limit was $5.5 \mathrm{~min}$.

\section{Discussion}

Our data show that the MAPT in water polo varies greatly from athlete to athlete and is therefore essential for a correct performance analysis.
The observations were acquired during two different world championships, therefore two years apart, and with different athletes in $38.6 \%$ of cases between the two editions. Despite this, no significant differences were found in the investigated variables (mean Game MAPT, mean Tournament MAPT and mean DI). Even between the teams, these values showed no significant differences. Therefore, given the large number of observations and the lack of significant differences between the two editions (2015 and 2017), the collected data can be considered very reliable for a definition of specific reference values of played time in water polo.

Being defined by the rules, the SAPT is the same for everyone, but a heterogeneous distribution of MAPT values is predictable within a single team. The results of this study show that a water polo player has on average a Game MAPT value of $17.4 \pm 6.1 \mathrm{~min}(54.6 \pm 9.5 \% \mathrm{DI})$. Moreover, the study is the first to highlight this water polo player mean value. Figures 1 and 2 clearly show the extreme variability of the time played by various players, which entails that the performance model could be variable besides affecting the training model.

The ability to produce high intensity activities and be able to repeat them is crucial in 
team sports (Bangsbo et al., 2006; Ben Abdelkrim et al., 2010; Spencer et al., 2005). A number of studies on water polo reveal that various tactical situations taking place during the game may affect play intensity (Escalante et al., 2013; Lupo et al., 2012; Ruano et al., 2016), which can also be influenced by other variables such as the competition level (Lupo et al., 2010; Platanou and Nikolopoulos, 2003), the margin of victory (Lupo et al., 2012), the starting quarter score (Gomez et al., 2014), and the match outcome (Lupo et al., 2011). All these aspects (intrinsic characteristics of the game) can influence the Game MAPT. Play intensity tends to decrease toward the end of the game as the effect of match-induced fatigue, both in water polo (Botonis et al., 2016a, 2016b; Melchiorri et al., 2010; Platanou and Geladas, 2006) and other team sports (Michalsik et al., 2015; Povoas et al., 2014; Montgomery et al., 2008) and playing time is a factor that influences matchinduced fatigue, which impairs the water polo player's performance (Botonis et al., 2018). The handling of players and substitutions by a coach play a key role in the attempt to control play time and therefore, maintain a good level of performance (Karcher and Bucheit, 2014).

Game MAPT's minimum and maximum values are very significant for coaches: there are athletes who play $2.3 \mathrm{~min}(7.1 \% \mathrm{DI})$ and others who play up to $31.6 \mathrm{~min}(95.3 \% \mathrm{DI})$. These significant differences have to be considered in training strategies: training should be based and constructed according to the MAPT of players. However, the MAPT must be assessed in every game because it may be different across games, as it can be affected by the substitutions. These considerations should be taken into account in order to improve coaching interventions in water polo (Burke and Mujika, 2014; Le Meur et al., 2012).

Data shown in Table 1 and especially those in Table 2, provide important information for technicians, coaches and researchers. Using interquartile range data (25th and 75th percentiles), coaches and researchers can get values for interpreting each athlete's effort. Statistical analysis suggests values of $12.6 \mathrm{~min}$ (25th percentile, lower limit) as a reference for a limited effort and $22.7 \mathrm{~min}$ (75th percentile, higher limit) as a high effort value.

The DI provides information on the percentage of the MAPT compared to the SAPT. These data are more practical for technicians and athletes and are interesting for future comparative studies with other team sports with free substitutions, but different SAPT (Ben Abdelkrim et al., 2007) or for comparing athletes of different competitive levels (Sindik, 2015). For example, in some European countries, the Under 15 water polo game has a SAPT of $7 \mathrm{~min}$ per time compared to 8 as in the case of older players, so the DI can be also useful for future comparative studies on the time played at different ages.

Only a slight relationship between age, Game MAPT and Tournament MAPT was found: older athletes tended to play more and this aspect should be also considered by the coach.

This study found significant differences between players' positions: Game MAPT, Tournament MAPT, and DI were greater in field players than in other positions (Table 3), and resulting data should be carefully considered by coaches, taking into account differences in performance among roles. Indeed, variations are revealed in covered distances, speeds, and blood lactate levels among water polo field positions (Melchiorri et al., 2010). These differences can be also found in the number of actions specific to the various positions, both in men and women, requiring different percentages of physical effort (Botonis et al., 2018). The same amount of MAPT could therefore involve a different physiological effort according to a player's position. The same difference in the physiological efforts of different players' position has been observed in other team sports (Karcher and Bucheit, 2014; Michalsik et al., 2015).

Data about training sessions or particular tournaments can be useful to the coach considering strategy and a training program design in tapering and peaking performance (Mujika, 2009). In shorter tournaments of 7-10 days (24-48 hours of rest between games), coaches should take into account Game and Tournament MAPT (considering the games played at the moment) value to avoid fatigue mismanagement which negatively affects performance (Botonis et al., 2018; Montgomery et al., 2008; Tanaka and Swensen, 1998). Instead, during a championship of several months, less engaged athletes in official competitions can receive over time a lower total number of training stimuli, given that the 
competition is one of the most intense stimuli to which the athlete is subjected.

Previous articles on the physiological profile of water polo players have only marginally considered MAPT (Melchiorri et al., 2010; Smith, 1998), meaning that future research on physiological demand of water polo should consider this type of data.

The limitation of this study is that only athletes with a particularly high competitive level were evaluated. In fact, the Omega timing system is active only during international competitions. However, we suggest that further studies should be extended to athletes of different competitive levels, from different age groups, and to female athletes.

\section{Conclusions}

This study is the first to define a reference value of the time played in elite water polo players. Significant differences in time played between positions were also highlighted. According to these data the values of physiological demand and game activity can be reconsidered and the training strategies should be adapted. The MAPT value corresponds to a quantitative type of value, fundamental in designing training programs, and can be helpful to manage recovery between matches and during a session or a tournament. The players' actual play times in a competition are so diverse that different training and recovery strategies have to be applied individualized to particular athletes. It is recommended that further studies be undertaken to find correlations between played time and the different situations determining the qualitative aspects of performance (tactics of play, game intensity in relation to the result, gender, etc.).

\section{References}

Ben Abdelkrim N, El Fazaa S, El Ati J. Time-motion analysis and physiological data of elite under-19-yearold basketball players during competition. Br J Sports Med, 2007; 41(2): 69-75

Ben Abdelkrim N, Castagna C, El Fazaa S, El Ati J. The effect of players' standard and tactical strategy on game demands in men's basketball. J Strength Cond Res, 2010; 24(10): 2652-62

Bangsbo J, Mohr M, Krustrup P. Physical and metabolic demands of training and match-play in the elite football player. J Sports Sci, 2006; 24(7): 665-74

Botonis PG, Toubekis AG, Platanou TI. Physical Performance During Water-Polo Matches: The Effect of the Players' Competitive Level. J Hum Kinet, 2016a; 54: 135-142

Botonis PG, Toubekis AG, Terzis GD, Geladas ND, Platanou TI. Performance Decrement and Skill Deterioration During a Water Polo Game are Linked With the Conditioning Level of the Athletes. J Strength Cond Res, 2016b; 30(4): 1033-41

Botonis PG, Toubekis AG, Platanou TI. Physiological and tactical on-court demands of water polo. J Strength Cond Res, 2018; Jun 14

Burke LM, Mujika, I. Nutrition for Recovery in Aquatic Sports. Int J Sport Nutr Exerc Metab, 2014; 24(4): 42536

Escalante Y, Saavedra JM, Tella V, Mansilla M, García-Hermoso A, Domínguez AM. Differences and discriminatory power of water polo game-related statistics in men in international championships and their relationship with the phase of the competition. J Strength Cond Res, 2013; 27(4): 893-901

FINA, Federation International de Natation. FINA Book, Water polo Rules, 2018. Available at http://www.fina.org/content/fina-rules-regulations; accessed on 02.02.2018

Franks IM, Goodman D. A systematic approach to analyzing sports performance. J Sports Sci, 1986; 4(1): 4959

Franks IM, Miller G. Training coaches to observe and remember. J Sports Sci, 1991; 9(3): 285-97

Galy O, Ben Zoubir S, Hambli M, Chaouachi A, Hue O, Chamari K. Relationships between heart rate and physiological parameters of performance in top-level water polo players. Biol Sport, 2014; 31(1): 33-8 
Gomez MA, DelaSerna A, Lupo C,Sampaio JE. Effects of situational variables and starting quarter score in the outcome of elite women's water polo game quarters. Int J Perform Anal Sport, 2014; 14: 73-83

Huges M. Essential of performance analysis in sport. Tailor \& Francis group, London, GB; 2015

Karcher C, Buchheit M. On-court demands of elite handball, with special reference to playing positions. Sports Med, 2014; 44(6): 797-814

Le Meur Y, Hausswirth C, Mujika I. Tapering for competition: A review. Science \& Sports, 2012; 27: 77-87

Lupo C, Tessitore A, Minganti C, Capranica L. Notational analysis of elite and sub-elite water polo matches. J Strength Cond Res, 2010; 24(1): 223-9

Lupo C, Tessitore A, Minganti C, King B, Cortis C, Capranica L. Notational analysis of American women's collegiate water polo matches. J Strength Cond Res, 2011; 25(3): 753-7

Lupo C, Condello G, Tessitore A. Notational Analysis of Elite Men's Water Polo Related to Specific Margins of Victory. J Sports Sci Med, 2012; 11(3): 516-25

Melchiorri G, Castagna C, Sorge R, Bonifazi M. Game activity and blood lactate in men's elite water-polo players. J Strength Cond Res, 2010; 24(10): 2647-51

Michalsik LB, Madsen K, Aagaard P. Technical match characteristics and influence of body anthropometry on playing performance in male elite team handball. J Strength Cond Res, 2015; 29(2): 416-28

Montgomery PG, Pyne DB, Hopkins WG, Dorman JC, Cook K, Minahan CL. The effect of recovery strategies on physical performance and cumulative fatigue in competitive basketball. J Sports Sci, 2008; 26(11): $1135-45$

Mujika I. Tapering and peaking for optimal performance. Human Kinetics. Champaign, IL (USA), 2009.

Omega Timing, Results 2015. Available at http://www.omegatiming.com/Sport?sport=aq\&year=2015, accessed on 19.10.2017.

Omega Timing, Results 2017. Available at http://www.omegatiming.com/Sport?sport=aq\&year=2017, accessed on 15.01.2018

Pinnington HC, Dawson B, Blanksby BA. Heart rate responses and the estimated energy requirements of playing water polo. J Hum Mov Stud, 1988; 15: 101-118

Platanou T, Nikolopoulos G. Physiological demands of water polo games with different level of competitiveness. In: Proceedings of the IX International Symposium of Biomechanics and Medicine in Swimming. Sant Etienne, France, 493-497; 2003

Platanou T. Time motion analysis of the international level water polo players. J Hum Mov Stud, 2004; 46: 319-331

Platanou T, Geladas N. The influence of game duration and playing position on intensity of exercise during match-play in elite water polo players. J Sports Sci, 2006; 24(11): 1173-81

Platanou T, Grasso G, Cufino B, Giannouris G. Comparison of the offensive action in water polo games with the old and new rules. In: Proceedings of the $12^{\text {th }}$ Annual Congress of the European College of Sports Science. Jyvaskyla, Finland; 2007

Portney LG, Watkins MP. Foundations of clinical research: Applications to practice. Upper Saddle River, N.J: Pearson/Prentice Hall, 2009.

Póvoas SC, Seabra AF, Ascensão AA, Magalhães J, Soares JM, Rebelo AN. Physical and physiological demands of elite team handball. J Strength Cond Res, 2012; 26(12): 3365-75

Póvoas SC, Ascensão AA, Magalhães J, Seabra AF, Krustrup P, Soares JM, Rebelo AN. Analysis of fatigue development during elite male handball matches. J Strength Cond Res, 2014; 28(9): 2640-8

Ruano MÁ, Serna AD, Lupo C, Sampaio JE. Effects of Game Location, Quality of Opposition, and Starting Quarter Score in the Outcome of Elite Water Polo Quarters. J Strength Cond Res, 2016; 30(4): 1014-20

Sindik J. Performance Indicators of the Top Basketball Players: Relations with Several Variables. Coll Antropol, 2015; 39(3): 617-24 
Smith H. Physiological fitness and energy demands of water polo: Time-motion analysis of goaltenders and field players. In: Proceedings of the Federation Internationale de Natation Amateur (FINA) First World Water Polo Coaches seminar. Lausanne, Switzerland: FINA, 183-207; 1991

Smith HK. Applied physiology of water polo. Sports Med, 1998; 26(5): 317-34

Spencer M, Bishop D, Dawson B, Goodman C. Physiological and metabolic responses of repeated-sprint activities: specific to field-based team sports. Sports Med, 2005; 35(12): 1025-44

Tan F, Polglaze T, Dawson B. Activity profiles and physical demands of elite women's water polo match play. J Sports Sci, 2009; 27(10): 1095-104

Tanaka H, Swensen T. Impact of resistance training on endurance performance. A new form of crosstraining. Sports Med, 1998; 25(3): 191-200

\section{Corresponding author:}

\section{Valerio Viero,}

Via Braies, 6400124 Roma -

Phone: 00393384723601

Fax: 00390633086459

E-mail: valerio.viero@gmail.com 